\title{
Interview
}

\section{An interview with Dr. Ruth Breeze and Dr. Florentina Taylor on foreign language teaching and learning}

\author{
Ricardo-María Jiménez \\ Universitat Internacional de Catalunya, Barcelona, Spain
}

Text received 8 September 2015; final version 14 September 2015

DOI: http://dx.doi.org/10.5565/rev/jtl3.649

\begin{abstract}
Dr. Ruth Breeze received her degree in Modern and Medieval Languages from the University of Cambridge and subsequently completed a master's degree from the same university. She has a $\mathrm{PhD}$ in language teaching from the University of Navarra. She was the Director of the Institute of Modern Languages at the University of Navarra until 2014, is currently a professor of English at the same Institute, and is a member of the GRADUN research group in the Institute of Culture and Society (ICS). Her publications focus on discourse analysis, language pedagogy - especially in higher education - and professional communication. Some of her recent research has focused on CLIL (e.g. Breeze et al., 2014).

Dr Florentina Taylor holds a PhD from the University of Nottingham, an MEd in TESOL from the University of Exeter, and Qualified Teacher Status for England. She currently works at the University of Greenwich as Senior Lecturer in Applied Linguistics and TESOL. She previously worked in the Department of Education at the University of York as a Teaching Fellow in TESOL, Lecturer in Language Education and MA TESOL Programme Leader. Her recent research mainly focuses on identity and self-perceptions, and their relationships to perceived relevance, motivation, engagement, uptake and achievement in foreign language education (e.g. Taylor, 2013).

The interviews were carried out in the summer of 2015, following up on previous conversations relating to education in general, SLA, ESL, CLIL, etc. during time spent by the author in Pamplona (Spain) as well as in Lancaster and York (United Kingdom). The interviews reflect some of the crucial points arising from these discussions.
\end{abstract}

\section{Interview}

Interviewer: You have both worked as foreign language teachers in your countries and are active researchers in the field. How important is it for teachers of foreign languages to engage in research? And how can they go about it?

Florentina Taylor: It is very important that teachers never stop learning, and never forget what it's like to be a beginner in any subject, but particularly in foreign languages. It is so easy to take things for granted and to get frustrated when a student doesn't remember something we 'covered' only last week! Listening closely to the experience of the person struggling to come to grips with content that to us might seem basic is, to me, a prerequisite to being a good teacher. There are many ways of doing this - from encouraging students to give ongoing informal feedback, to conducting small action research projects, collaborating with colleagues and external researchers, reading relevant research papers or attending conferences and workshops. It is very important that language teachers are aware of the research evidence that supports - or does not support - their teaching and assessment methods. However, teachers cannot keep up to date with the latest research, or conduct research of their own, 
without solid support from their institutions. They cannot be expected to develop their research literacy in their own free time (which is already very limited), therefore institutional encouragement and commitment are crucial.

Ruth Breeze: To get more satisfaction from teaching, we need to learn to think more about what we do. At the very basic level, this means talking to our students and colleagues about what goes on in the classroom. This should lead naturally to a certain mode of enquiry, and to a kind of interested engagement with what other people are doing, either through reading, attending courses and conferences, or conducting small projects designed to improve aspects of our teaching or implement innovatory practices. As Florentina says, institutions should support this by dedicating time to teachers' ongoing professional development, and by actively encouraging involvement in research and development.

Interviewer: What are some of the hot issues that need answering in the broad field of foreign language teaching and learning?

Ruth Breeze: One of the challenges facing us at the moment is that of addressing the interplay between EMI, CLIL and language teaching. This is important on several different levels. First, administrators and organisers need to know that English medium instruction does not replace formal language teaching. CLIL, at least in theory, is supposed to integrate the two (hence the "I"), but many programmes that are billed as CLIL turn out to be EMI, since no attempt is made to integrate any support for language learning. In most content courses delivered in English in European higher education, the students are given no help at all with the language - of course, incidental learning may take place, just as it might in any immersion situation, but it would be wrong to describe such EMI courses as CLIL. Second, the providers of language courses need to think more about how these are going to help students become effective professionals. That means that they need to understand professional discourse communities, learn more about how different groups of people communicate with each other. They need to continue along the established lines of ESP research and practice, but also build positive synergies with other research traditions in the area of professional communications. Third, we need to consider how both of these issues should influence teacher training - training for EMI teachers, training for CLIL teachers, and training for language teachers.

Interviewer: You both have done research focusing on teacher or learner perspectives in foreign language teaching and learning. Why does listening to our students' and teachers' voices really matter?

Florentina Taylor: According to an old saying, in order to truly understand someone, you need to walk a mile in their shoes. Listening to our students' and teachers' voices through research is the closest we can get to being in their positions. They are the main stakeholders in the education process - it makes no sense to devise policies and recommendations for practice without having as good an understanding as we can get of what it is like to be a student or a teacher in that particular context. There is prolific evidence showing that students and teachers who feel they matter as individuals are more engaged, more productive, happier and more willing to collaborate and work hard (e.g., Deci and Ryan, 1985; Kohn, 1993; Taylor, 2013). It is basic common sense, isn't it, but another old saying tells us nothing is less common than common sense... 
Ruth Breeze: Listening to our students is not only important in terms of developing empathy, understanding their feelings and making sure their concerns are addressed. We can also learn about the ways different people approach the task of learning a new language, what strategies they use, and how they overcome the difficulties that arise. It is surprising that mainstream research has ignored some aspects that are fundamental for students, probably because they are perceived to go against the received opinion about what should be done in the classroom. For example, if you pick up most standard textbooks on English language teaching, they will tell you that students do not like being corrected, because it makes them anxious and interrupts the flow of communication. A PhD student of mine recently conducted a research project into student expectations, and found that students in Spain expressed a strong desire to be corrected by their teachers. She also found that teachers' perceptions of the way they corrected students actually differed quite sharply from what they really did in the classroom. Her research is an example of how listening to students can make us question the "orthodoxies" of language teaching and work towards a deeper understanding of good practices.

Interviewer: Both Spain and England have a reputation for having poor results in foreign language teaching and learning. What could be some of the reasons for this?

Ruth Breeze: I have to say that Spain is far ahead of the United Kingdom in language teaching and learning. Modern languages have been neglected over the last thirty years, probably as a result of the underlying view that "everybody learns English". This is quite short-sighted, and will probably have long-term consequences for British education. It's time the British acknowledged the incalculable value of learning another language, and of having access to other cultures and ways of thinking.

Florentina Taylor: I wouldn't say they have a poor reputation for teaching. Language teachers work very hard, with very limited resources, but we all know there is a big difference between what gets taught and what gets learnt - for a number of reasons. Besides, assessment, which is often not something that classroom teachers can influence, can have a detrimental impact on the focus and methods of teaching, as well as on students' engagement. Educational policy is also sometimes perceived as disconnected from the realities of the classroom, or from the research evidence about 'what works' in language teaching and learning.

In English-speaking countries, there is also the myth that 'everybody speaks English nowadays, therefore we don't need to learn foreign languages', which is, of course, not true. English is only the third most spoken language in the world today, after Mandarin and Spanish. It is a myth that is to an extent very convenient, but also very dangerous. It is true we can get away with speaking English in many large cities around the world, but outside them it is a different matter. Learning a language is hard work, requiring a huge amount of effort and commitment. Clinging on to the belief that 'the other' will always be willing to make the effort for us and speak our language means we may give up before even trying. But not only is it unfair to always expect somebody else to make the effort and speak our language, it is also disrespectful and reminiscent of historic attitudes that many people are trying to forget.

And there is so much more to language learning than being able to function while travelling abroad! Research shows that knowledge of other languages helps boost literacy and reasoning skills, slows down the decline of cognitive functions, and helps develop more positive attitudes towards the communities speaking those languages. Having even limited knowledge 
of other languages and cultures can make us better people - more understanding and more willing to cooperate. This is extremely important in a world that continues to suffer too much from lack of genuine communication and mutual understanding.

Interviewer: Could you tell us a little about your current research in this field?

Ruth Breeze: Last year I was involved in a research project about how primary school teachers adapt to the implementation of external testing systems. It was somewhat surprising for me that almost all the teachers were positive about the fact that their pupils were taking an exam organised by an international examination board, and regarded this as useful in helping them to set goals, balance classroom activities and motivate students. Currently I am working on a project in which we look at how accuracy improves across CEFR levels - of course, speakers become more accurate, but the progression is slow, and people may still make basic mistakes (such as forgetting to use "s" in the third person present) at higher levels. Our study tracks this process and provides some useful pointers for teachers and examiners.

\section{References}

Breeze, R., Llamas Saíz, C., Martínez Pasamar, C., \& Tabernero Sala, C. (Eds.) (2014). Integration of theory and practice in CLIL, Ámsterdam: Rodopi. B.V.

Deci, E. L., \& Ryan, R. M. (1985). Intrinsic motivation and self-determination in human behavior. New York: Plenum.

Kohn, A. (1993). Punished by rewards: The trouble with gold stars, incentive plans, A's, praise and other bribes, Boston: Houghton Mifflin.

Taylor, F. (2013). Self and identity in adolescent foreign language learning. Bristol: Multilingual Matters.

\section{Author information:}

Ricardo-María Jiménez is a Faculty member at the Universitat Internacional de Catalunya, Barcelona, Spain, where he teaches legal discourse and communication skills. He has been working as a secondary school teacher at Viaró school (Sant Cugat del Vallès, Spain) for many years. He is also an external collaborator of ICS (University of Navarra). He has been a Visiting Researcher at CASS (Centre for Corpus Approaches to Social Science, University of Lancaster) and he is currently completing his PhD at the University of Navarra.

Email: rmjimenez@uic.es

To cite this article:

Jiménez, R-M. (2015). An interview with Dr. Ruth Breeze and Dr. Florentina Taylor on foreign language teaching and learning. Bellaterra Journal of Teaching \& Learning Language \& Literature, 8(3), 99-102. DOI: $\underline{\mathrm{http}: / / \mathrm{dx} . \text { doi.org/10.5565/rev/jt13.649 }}$ 